In: Rainer, Franz; Gardani, Francesco; Luschützky, Hans Christian; Dressler, Wolfgang U. (Hrsg.): Morphology and meaning : selected papers from the 15th International Morphology Meeting, Vienna, February 2012. John Benjamins: Amsterdam 2014, S. 191-204; ISBN 978-90-272-4846-6, EISBN 978-90-272-7093-1, DOI:10.1075/cilt.327

Manuskriptversion

\title{
Compounds vs. phrases: The cognitive status of morphological products
}

Sven Kotowski, Katja Böer \& Holden Härtl

Universität Kassel

Suggested running head: "Compounds vs. phrases"

\begin{abstract}
Nominal compounds and corresponding phrases provide a suitable test bed for inquiry into the interface and demarcations between syntax and morphology. In this article we show that the distinction between the two constructions is blurred from a theoretical perspective and investigate processing and cognitive aspects. After an examination of structural as well as semantic properties of the two types, we report on three studies (memorization, questionnaire, and reading time) that experimentally juxtapose German adjective-noun constructions of phrasal and morphological kinds. The results of these studies indicate cognitive differences between compounds and phrases. Considering alternative explanations, we argue that our data supports the view of two separated structural levels of grammar.
\end{abstract}

\section{Introduction}

The issue of compounding features prominently in ongoing debates about the nature of and the demarcations between syntax, morphology, and the lexical system. While several authors dispute the existence of boundaries between these alleged linguistic subcomponents (Lieber 1992; Höhle 1982; Schlücker \& Plag 2011), others argue in favor of a modularized perspective, i.e., an isolation of morphological structure building and, in particular, word formation (cf. Di Sciullo \& Williams 1987; Ackema \& Neeleman 2004; Wunderlich 1986). The debate centers around several structural aspects, e.g., the possibility of syntactic access to word-internal constituents (for discussions of the principle of lexical integrity cf. among others Lieber 1992, Giegerich 2006; Booij 2009) as well as possibly diverging semantic and pragmatic properties of morphological and syntactic structures (cf. Wunderlich 2008; Bücking 2009; Gunkel \& Zifonun 2009). In this context, nominal compounds and corresponding phrases provide a suitable test bed for investigation. As will be shown, however, several factors that are oftentimes called upon to theoretically distinguish the two constructions have to be second-guessed regarding their validity, leaving us with no clear indication as to an answer of how to disentangle morphological and syntactic structure building. As a promising 
route out of this impasse we suggest to investigate processing aspects, which are insightful regarding the cognitive foundations of morphological and syntactic operations. Our experimental data show processing differences between compounds and phrases, which possibly indicate a distinct affinity towards lexicalization and, in turn, functional properties.

The paper is structured as follows: Section 2 recapitulates some of the more prominent properties of compounds and phrases, which are often discussed in the context of the above distinction between morphology and syntax. Section 3 reports on three studies with German adjective-noun constructions (AN) — compounds and phrases — that suggest distinct treatments for the respective complexes. Here, implications of the experimental results are considered as well. Section 4 concludes the discussion.

\section{Grammatical, semantic, and pragmatic properties of compounds and phrases}

Before reviewing some of the (pre-)theoretical observations concerning the boundary between word-formation and syntax, a general note of caution seems in place. As recently argued (cf. Haspelmath 2011; Jacobs 2011), discussions of said boundary are oftentimes inherently circular, as they presuppose an unambiguous definition of which units are words and which syntactic constructions above word-level. Arguments to that effect therefore had to a priori acknowledge the boundary to exist. However, Haspelmath (2011) as well as Jacobs (2011) both emphasize the value and necessity of the word as a tool and vantage point for linguistic inquiries, bearing in mind that it is bound to a specific language system. We take the examples presented in the following arguments, especially those from German, to indeed be based on valid assumptions concerning their respective status as either phrases or compounds.

\subsection{Morpho-syntactic and phonological properties}

German AN-constructions provide a clear-cut means of determining their respective status as either compounds or phrases. The adjectival element is morphologically reduced, surfacing as a stem in compounds such as Grünspecht ('green_woodpecker'), while carrying an 
inflectional suffix in phrases, e.g., Grüne Sauce ('green sauce', i.e., 'salsa verde'). This is also reflected orthographically as the great majority of German compounds is written as one word.

German differs in these respects from inflectionally less rich languages, e.g., English. Here, authors oftentimes resort to phonological distinctions along the opposition of the compound and nuclear stress rules (cf. Chomsky \& Halle 1968). Due to multiple exceptions to these rules, such as morning páper or Boston márathon (cf. Plag et al. 2008), however, stress is often dismissed altogether as a sufficient criterion for keeping apart phrases and compounds (cf. Bauer 1998; Spencer 2003; see also Plag 2010 and Arndt-Lappe \& Bell 2012 for recent proposals on the analogy-driven, lexicon based nature of stress assignment). Others analyze right-stressed constructions as phrases (cf. Marchand 1969; Payne \& Huddlestone 2002) or assign them compound status but syntactic provenance (cf. Giegerich 2006).

Tests regarding lexical integrity seemingly provide insights into properties of both phrases (1(b.)) and (synthetic) compounds (1(b.)), with only the latter obeying the principle. As pointed out by Gaeta (2012), however, a construction's grammatical status is of secondary interest only here, while the crucial distinction is rather to be found in the opposition of lexicalized (1(c.)) and non-lexicalized (1(d.)) constructions (cf. also Schäfer 2011):

(1) a. *Henry owns a greenhouse and Mary owns a red one.

b. Henry owns a green house and Mary owns a red one.

c. La liberazione di Rugova è una [mina [anti-USA $\left.A_{\mathrm{i}}\right]$, che $e_{\mathrm{i}}$ hanno sostenuto l'UCK per scardinare un equilibrio instabile.

'The liberation of Rugova is an anti-USA $A_{i}$ threat, who ${ }_{i}$ have supported the UCK to upset an unstable equilibrium.'

d. $\quad$ *Ho una camicia blu di Prussia $a_{\mathrm{i}}$ ma non ci $i_{\mathrm{i}}$ vado mai.

'I have a Prussiain blue shirt, but I never go there ${ }_{\mathrm{i}}$.'

Thus, neither stress nor the notion of lexical integrity are dependable factors in distinguishing between compounds and phrases. If lexicalization, or the lack thereof, explains syntactic access to word-internal structures, we need to determine the interplay between lexicalization, word-formation, and functional properties, as reflected in the particular naming function of compounds, which the following section will be devoted to.

\subsection{Semantic-pragmatic aspects}


A common semantic distinction between the two constructions relates to the assumed name giving function of compounds, e.g., whiteboard, and the descriptive nature of phrases, e.g., white board (cf. Klos 2011; Levi 1978; Zimmer 1971). Due to numerous counterexamples, however, this can only be a tendency. For example, the presumably phrasal complex best $\operatorname{man}^{1}$ is at the same time the lexicalized name of a certain concept, i.e., groomsman, while a compound such as terror $d a d^{2}$ is a non-established, ad hoc creation, as commonly found in newspaper headlines. A construction's denotation therefore cannot unambiguously predict its grammatical status.

Yet, compounds apparently have a stronger affinity to display meaning specializations and to be read as kinds (cf. Bücking 2009; Gunkel \& Zifonun 2009; Levi 1978), which can be read off from their distinct behaviors in certain constructions. For example, a phrase containing a deverbal as in Max is a sweet tálker can receive an intersective as well as a non-intersective reading, whereas the corresponding compound in Max is a swéet talker is preferentially interpreted non-intersectively (cf. Schäfer 2009). While the phrase can either denote a person that is sweet and a talker or someone who talks sweetly, the compound allows for the latter, non-intersective reading only.

Moreover, novel compounds appear more readily compatible in generic contexts with kind selecting predicates such as be extinct or be invented (cf. Bücking 2009: 272-273; for kind selecting predicates see Krifka et al. 1995; Müller-Reichau 2006). Pre-theoretically, a novel compound such as Blaubuch ('blue_book') intuitively suggests itself to be interpreted as a lexical name, whereas a non-lexicalized phrase like blaues Buch ('blue book') receives a descriptive interpretation. Thus, only the novel compound preferentially triggers a kind reading, introducing a new concept upon coinage (cf. Schlücker \& Hüning 2009: 221; see also Lipka 1977). Such distinct properties in novel contexts can possibly be explained by the nature of kind referring NPs, which are always semantically connected to well-established kinds (cf. Krifka et al. 1995: 11-12; for the notion of being well-established see MüllerReichau 2006: 88). Therefore, linguistic realizations of kinds are usually lexicalized or suggest lexicalization, respectively. Following Gunkel \& Zifonun (2009), it is complex common names that typically denote subkinds of the kind denoted by the head, for which they rely on a relational modifier-head connection. Crucially, such modifier-head relations, often shifted in their semantic compositionality, are typical for compounds: Modification at the lexical level prototypically introduces an underspecified, mediating function between 
predicates - and hence meaning specialization - while at the phrasal level an identity or intersective relation is prototypically instantiated (cf. Bücking 2009: 256-257). ${ }^{3}$

The affinity of compounds to name kinds does not imply that phrases cannot also refer to kinds, e.g., grüner Tee ('green tea') or Kleiner Tümmler ('harbor porpoise'). Such "phrasal names" are also lexicalized, which is - as argued above - a prerequisite for qualifying as a name. However, when used as novel expressions in kind-selecting environments, be it as an adjective-noun compound or an adjective-noun phrase, we diagnose a clear difficulty for phrases to express a kind: Die ?? schwarze Hyäne / Schwarzhyäne ist seit langem ausgestorben ('The black hyena / black_hyena has long been extinct') (cf. Bücking 2009; Klos 2011). From a theoretical perspective, it is indeed a yet unsolved issue why such phrasal names seem to be able to enter the mental lexicon under special, somehow impeding conditions only.

In summary, neither from a grammatical, phonological nor semantic-pragmatic perspective can we identify clear-cut differences between the respective properties of established compounds and phrases. A potential way out of this theoretical impasse is to investigate into processing aspects and the cognitive status of the two constructions. The following sections report on three experimental studies, which support the distinction between separated structural levels of grammar, be they labeled "morphology" and "syntax" or not.

\section{Investigations into cognitive differences between compounds and phrases}

As Wunderlich (2008: 252) remarks with regard to frequency effects, semantically nontransparent morphological products are oftentimes processed faster than transparent syntactic expressions as long as they occur frequently enough. Most compounds fall under the former category (see 2.2). Although the according differences are of preferential rather than absolute nature, such treatments may well relate to the predominant naming function of compounds in opposition to the - at large - descriptive quality of syntactic phrases. Processing discrepancies along these lines were therefore hypothesized to also be at play in three studies on German AN-constructions. 
Experiment 1 was a learning study ${ }^{4}$ - using E-Prime software — conducted in German and divided into two phases. In a learning phase, subjects were asked to memorize prototypical pictures of everyday objects, such as a saw or a comb, in combination with either a not established AN-phrase (e.g., eine hohe Axt ('a high axe')) or an AN-compound label (e.g., ein Tiefbesen ('a deep_broom')). Afterwards, in a recall phase, subjects were asked to decide on whether the picture-label combinations they were presented with then-either learned or unlearned combinations - matched or did not match the learned material. The entire procedure was repeated three times over the course of three days for each subject to provide a suitable test bed for hypothesized processing and memorization differences. The response variables were the "correctness" of the answers and the reaction times needed to decide via keystroke.

Statistical analysis (ANOVA) revealed a main effect for memorization. Thus, learned items, phrases as well as compounds, were decided faster than unlearned ones $(p<.001)$ and subject performance got better over the course of the three sessions $(p<.001)$. Furthermore, phrases were overall decided faster than compounds $(p<.01)$, again an expected result because of the semantic intransparency (cf. 2.2) of novel compounds.

There was no significant interaction between memorization and item type: Neither item type was memorized better over time $(p<.26)$. However, in post hoc analysis we extricated an interesting finding from a general comparison between learned and unlearned items, i.e., if a certain picture-label combination had been presented in a learning phase or not, with the distinction between $\mathrm{AN}$-compounds and AN-phrases. While neither item type was memorized better over time, we observed a memorization effect analyzing the overall results from the overall time window (the interaction for LEARNED $\times$ ITEM TYPE reached marginal significance at $p<.09$ ): Unlearned compounds took longer to decide than unlearned phrases. This effect is highly significant $(p<.001)$. Crucially, this difference disappears with learned compounds: These were processed just as fast as learned phrases $(p<.67)$. We attribute this result to a stronger memorization effect for novel compounds. While novel compounds are difficult to process, unknown phrases are not, but compounds pronouncedly gain in processability as soon as they are learned, such that they become accessible just as effortlessly as phrases. This is also indicated by a comparison of the significance levels of learned and 
unlearned compounds, which reached $p<.001$, versus learned and unlearned phrases with $p<$ .01 . Moreover, the memorization effect is reflected in the error rates, where a comparison of the error numbers for learned compounds as opposed to unlearned ones (interaction of LEARNED $\times$ ITEM TYPE: $p<.001)$ with those for learned and unlearned phrases reveals that compounds profited significantly from learning $(p<.05)$, whereas phrases did not $(p<$ $.75)$, and that learned compounds were decided as correctly as phrases $(p<.99)$.

The results suggest processing differences between novel AN-compounds and phrases, which may be of structural or semantic provenance, and therefore support a lexicalist view of the build-up of the language faculty and a separation of syntax and morphology (cf. also Clahsen \& Almazan 2001; Mondini et al. 2002; Wunderlich 2008). AN-compounds are probably more difficult to process due to their linguistic markedness, which is supported by their tendency to encode specialized meanings (see 2.2). Memorization, however, apparently evens out this markedness effect, up to the point at which we no longer find processing differences between learned items of either type. Following the reasoning presented in 2.2, this is in accordance with hypotheses regarding the peculiar quality of compounds as prime suggestions for lexicalization.

\subsection{Experiment 2: Questionnaire study}

Experiment 2 explored how salient the different AN-constructions are in discourse. We hypothesized novel compounds to display higher discourse salience in comparison to their phrasal counterparts, since a higher degree of linguistic markedness can be ascribed to them. Marked linguistic expressions exhibit a higher accessibility in discourse, which may manifest itself, for example, in pronoun resolution: The more salient a potential antecedent, the more likely it will be selected for referential resolution of a succeeding pronoun (cf. among others Greene et al. 1992; Härtl 2008).

In order to test this hypothesis we carried out a questionnaire study, utilizing verbs of implicit causality, which provide a suitable test bed for our purposes. From a processing vantage point, such constructions include (causative) psych-verbs like fascinate or frighten ((2)a.) as well as (stative) psych-verbs such as appreciate or fear ((2)b.): 
(2) abigail ATIM fascinates Jonathan $_{\mathrm{EXP}}$

b. $\quad$ Abigail $_{\mathrm{EXP}}$ fears Jonathan ${ }_{\mathrm{STIM}}$

These have been argued to trigger a strong bias as to which participant role causal attributes are assigned (cf. among others Brown \& Fish 1983; Härtl 2008). Sentence ((2)a.) contains a stimulus-experiencer verb (S-E verb), sentence ((2)b.) an experiencer-stimulus verb (E-S verb). If sentences like (2) are followed by a because-clause explicating the cause for the psychological state expressed in the main clause, a strong expectation on the clausal relation is created through the semantic properties of the verb. Thus, for example, we expect to learn more about Jonathan (stimulus) in sentence ((2)b.) and why he is feared by Abigail. The choice of attribution is indicated by the corresponding pronoun in the because-clause. In sentence ((2)a.) we expect to learn more about Abigail, correspondingly. While we expect clausal attributes in $((2)$ b.) to be assigned to the stimulus, as displayed in (3), pronominal resolution as in (4) is unexpected and triggers higher processing costs (cf. Härtl 2008):

(3) Abigail fears Jonathan because he often throws stones at her.

(4) Abigail fears Jonathan because she generally fears boys.

Measuring discourse salience, our hypothesis was that novel compounds in stimulus position-due to their pronounced conceptual status in comparison to phrases - trigger an increase in the assignment of causal attributes. Experiment 2 consisted of 24 German test sentences - using the same AN-constructions as in Experiment 1 (see 3.1)-and 24 fillers (containing non-psychological activity verbs like paint and novel NN-compounds, e.g., chair roof). Test sentences contained 6 E-S and 6 S-E verbs, each of which combined with 6 compounds and 6 phrases, respectively, as illustrated in (5):
a. Die flache Säge begeistert Christoph, weil [ sie |er] ... 'the flat saw fascinates Christoph because [it $\mid$ he]'
b. Johanna schätzt das Schmalmesser, weil [sie | es ] ... 'Johanna appreciates the slim_knife because $[$ she $\mid$ it]'

Participants were 21 undergraduate students whose native language was German. They were instructed to complete the sentences using one of the two given pronouns, thus indicating the causal attribution to either stimulus or experiencer. The pronouns were given to avoid attribution to an extra-clausal referent, e.g. because it is raining. 
As expected, statistical analysis indicates a highly significant main effect $(p<.001)$ for verbs of implicit causality, i.e., pronouns referring to the stimulus were more often used for sentence completion than those referring to the experiencer. We also found a (marginally) significant effect with regard to compounds: The probability to relate the because-sentence to the stimulus position was even higher when it was filled by a compound $(p<.09)$. This suggests a tendency for novel compounds to be more salient than phrases. However, the reason for this is not immediately accessible, since phrases and novel compounds differed in at least two features, i.e., structurally (compound or phrase) and semantically. For example, with regard to semantic differences we neither know what a deep comb nor what a deep_comb is, yet, we arguably know more about the prototypical relationship of modifier and head in a phrase (i.e., descriptive) than in a compound (see 2.2). To allow for a semantically more fine grained analysis we designed a reading time experiment.

\subsection{Experiment 3: Self-paced reading study}

Experiment 3 was designed to not only disentangle differences between compounds and phrases in terms of discourse salience, but also between novel and established compounds as well as between semantically marked and unmarked phrases. In a self-paced reading study, using sentences similar to Experiment 2 (3.2), we expected to find differences in RTs on the pronoun in the because-clause depending on the respective AN-construction in the main clause.

\subsubsection{Method}

We again utilized sentences containing verbs of implicit causality, followed by a becauseclause. All verbs were of the E-S type and the experiencer position was filled by an ANconstruction. The four different AN-constructions, exemplified in (6) were unmarked compounds and phrases as well as marked (and novel) compounds and phrases:
a. Der Weitlehrer
'the wide_teacher'
b. Der tiefe Arzt

MARKED COMPOUND

MARKED PHRASE 
'the deep doctor'
c. Der Langläufer
UNMARKED COMPOUND
lit. 'the long_runner' (the cross-country skier)
d. Der starke Schmied
UNMARKED PHRASE
'the strong blacksmith'

These four conditions aimed at further unscrambling structural from semantic features in terms of discourse salience. The constructions were tested for novelty and semantic markedness. ${ }^{5}$ We used 40 test items - 10 for each AN-category-and 40 filler sentences. The latter displayed the same syntactic structure as the critical sentences but contained nonpsychological activity verbs (hug, support etc.), which do not trigger an implicit causality effect. In the test sentences, pronouns in the because-clause referred to the experiencer position, thus, the sentences ended unexpectedly (see 3.2):

(11) Der starke Schmied fürchtet Ina, weil er Angst vor erfolgreichen Frauen hat. 'The strong blacksmith fears Ina because he is afraid of successful women'

The participants, 27 undergraduate students whose native language was German, were instructed to self-paced-read the sentences, i.e., words were presented individually on a screen and participants initiated the next word via keystroke. Read sentences were followed by a semantic comprehension question, which referred to a random constituent of either the main or the subordinate clause (e.g., Does Ina fear successful women?). Participants were told to not be disturbed by possibly odd words but to proceed quickly and keep track of what they were reading in order to be able to answer the question. RTs were measured for each word. We expected faster RTs on the pronouns for novel compounds and marked phrases in experiencer position should semantic factors be responsible for the differences in discourse salience. Should, however, structural factors trigger an increase in discourse salience, we expected generally faster RTs for compounds than for phrases.

\subsubsection{Results}

In the ANOVA only test items in which the comprehension question was answered correctly were included. The overall error rate was at 4.7 per cent. Contrary to expectations, there was no significant difference in RTs on the pronoun position, neither across nor within subjects. Statistical tendencies in the expected direction occurred only after the pronoun position, 
which was, however, not reliable. Therefore, we conducted post hoc analysis for the position of the AN-construction in the main clause, see example (11), analyzing only those constructions which contained three to five syllables. On this position, statistical analysis revealed a significant interaction between markedness and item type $\left(F_{1}(1,26)=44.1, p<\right.$ $.001)$, see Figure 1 .

\section{@@ Insert Figure 1 here}

The main effect for markedness was also highly significant: Marked (and novel) compounds (e.g. wide_teacher, see (6) above) and marked phrases (deep doctor) were read slower than unmarked compounds (long_runner) and unmarked phrases (strong blacksmith) $\left(F_{1}(1,26)=\right.$ 102.1, $p<.001$ ). Importantly, as revealed by pairwise comparisons, RTs for unmarked compounds and unmarked phrases did not differ $(t(26)=.2, p<.99)$. Marked compounds, however, were read slower than marked phrases to a highly significant extent $(t(26)=9.77, p$ $<.001)$. This supports the claim that novel compounds are "more marked" than comparable phrases. Marginally significant was the effect that participants took longer to read marked phrases than unmarked ones $(t(26)=2.5, p<.05)$.

\subsubsection{Discussion}

Aiming at disentangling structural and semantic differences by comparing not only compounds and phrases but also different semantic conditions within these structures, the experiment did not yield the expected results. As suggested in the discussion at the IMM $15,{ }^{6}$ this might be down to an overload of marked structures. Thus, refinements could possibly be achieved by reducing the material's markedness, which is not only present in marked phrases and novel compounds, but also in the unexpected attribution of the because-clause. Further suggestions pointed at running the experiment with "minimal pairs" of compounds and phrases $^{7}$ to minimize semantic differences between both constructions. Experimentally separating opaqueness from compounds seems difficult, though, since opaqueness apparently is one of the core features of prototypical compounds themselves (see 2.2).

Regarding the expected effects for markedness and novelty in the RTs for different ANconstructions, it seems intuitively predictable for marked constructions to be read slower than unmarked ones. Notably, however, marked compounds were read slower than marked phrases, even though for reasons not yet fully understood. Here, either structural or 
transparency differences could be at the bottom of this effect: Assuming that compounds exhibit a higher level of semantic opaqueness than phrases, this supports the intertwined nature of semantic and structural factors in the issues at hand. It seems possible, however, that effects of novelty and markedness somehow add up in novel compounds, which in turn leads to the slower reading times we observed in this condition. General reading differences could also be responsible for the observed results. For example, compound words have been shown to differ regarding gazing durations as well as recognition and reading times from complex as well as monomorphemic words (cf. Inhoff et al. 1996), while lexical access of individual intra-compound constituents also plays a role in word recognition when compared to simplex words (cf. Inhoff et al. 2008). Future research needs to bear in mind such differences and further aim at clarifying their influence on the distinction between compounds and phrases in psycholinguistic experiments.

\section{Conclusion}

This paper contributes to the ongoing discussion whether syntax and morphology must be considered separate components of the language system from a theoretical as well as psycholinguistic perspective. Results of Experiment 1 imply that novel AN-compounds are linguistically more marked than comparable AN-phrases, but can effectively overcome processing difficulties confounded with linguistic markedness in the course of memorization. Experiment 2 shows that novel AN-compounds behave differently from phrases in terms of discourse salience, which can possibly also be attributed to the markedness of these novel structures. A similar tendency is observable in the post hoc analysis of the AN-constructions' RTs in Experiment 3. Our data again suggest that novel AN-compounds exhibit a greater degree of linguistic markedness than comparably marked phrases, an effect which disappears with unmarked and established expressions. While we propose structural and semantic reasons underlying both our observations, it remains unclear whether structure building and semantics need to be understood as an interdependent complex or could, in principle, be kept separated from one another. This problem is not only theoretically intriguing but also experimentally challenging, since there is apparently no straightforward solution on how to eliminate intertwining effects of such nature in compounds. 


\section{Notes}

\footnotetext{
${ }^{1}$ We classify this construction as syntactic due to the adjective's superlative form.

${ }^{2}$ Note that the non-descriptive nature of compounds seems particularly clear in the example of terror dad, being semantically highly intransparent. Thus, the source it is taken from does not aim at evoking a reading such as $a$ dad who is a terrorist or who terrorizes, but the interpretation of dad of a terrorist. Source: New York Post on the web; date: July 22, 2011. Last accessed January 20, 2012.

$<$ http://www.nypost.com/p/news/local/mohammed_zazi_found_guilty_justice_r4MPUYPoyz4wG2VM0khoOJ

${ }^{3}$ See Gunkel \& Zifonun (2009: 208-209) for constructions, also of syntactic provenance, that can feature as complex common names. For relational adjectives in German that inevitably establish underspecified modifierhead relations see Schlücker \& Hüning (2009: 217-219).

${ }^{4}$ The account here will be of result-oriented nature. For a detailed report on this experiment, including method, setup, and used material see Böer et al. (2012).

${ }^{5}$ In a questionnaire study we used novel, non-established AN-complexes and asked participants how well they were able to assign an interpretation to these items (as well as 40 fillers). We used the 10 compounds and phrases which received the lowest scores in this rating for the actual study. Note, however, that it is important to observe that markedness and novelty of a compound are confounded to some extent, see 3.3.3 for discussion.

${ }^{6}$ We thank the audience of the IMM 15 for a fruitful discussion.

7 An example for such a minimal pair in German would, e.g., be grüner Tee vs. Grüntee ('green tea' vs. 'green_tea').
}

\section{References}

Ackema, Peter \& Adriaan Neeleman. 2004. Beyond Morphology. Interface Conditions on Word Formation. Oxford: Oxford University Press.

Arndt-Lappe, Sabine \& Melanie Bell. 2012. "Explaining English Compound Stress Analogically". Talk held at the $15^{\text {th }}$ International Morphology Meeting, Vienna.

Bauer, Laurie. 1998. "When is a Sequence of Two Nouns a Compound in English?". English Language and Linguistics 2:1. 65-86.

Booij, Geert. 2009. "Lexical Integrity as a Formal Universal: A Constructionist View". Universals in Language Today, ed. by Sergio Scalise, Elisabetta Magni \& Antonietta Bisetto, 83-100. Berlin: Springer.

Böer, Katja, Sven Kotowski \& Holden Härtl. 2012. "Nominal Composition and the Demarcation between Morphology and Syntax: Grammatical, Variational, and Cognitive Factors". Anglistentag 2011 - Proceedings. ed. by Monika Fludernik \& Benjamin Kohlmann, 63-74, Trier: Wissenschaftlicher Verlag.

Brown, Roger \& Deborah Fish. 1983. "The Psychological Causality Implicit in Language". Cognition 14. 237-273.

Bücking, Sebastian. 2009. "German Nominal Compounds as Underspecified Names for Kinds". Linguistische Berichte Sonderheft 17. 253-281.

Chomsky, Noam \& Morris Halle. 1968. The Sound Pattern of English. New York: Harper and Row.

Clahsen, Harald \& Mayella Almazan. 2001. "Compounding and Inflection in Language Impairment: Evidence from Williams Syndrome (and SLI)". Lingua 111. 729-757.

Di Sciullo, Anna M. \& Edwin Williams. 1987. On the Definition of Word. (= Linguistic Inquiry Monographs 14.) Cambridge, MA: MIT Press.

Gaeta, Livio. 2012. "NN Compounds in Italian and Beyond". Talk held at the $15^{\text {th }}$ International Morphology Meeting, Vienna. 
Giegerich, Heinz. 2006. "Attribution in English and the Distinction Between Phrases and Compounds". Englisch in Zeit und Raum - English in Time and Space: Forschungsbericht für Klaus Faiss, ed. by Petr Rösel, 10-27. Trier: Wissenschaftlicher Verlag Trier.

Greene, Steven B., Gail McKoon \& Roger Ratcliff. 1992. "Pronoun Resolution and Discourse Models". Journal of Experimental Psychology: Learning, Memory, and Cognition 18. 266-283.

Gunkel, Lutz \& Gisela Zifonun. 2009. "Classifying Modifiers in Common Names". Word Structure 2:2. 205-218.

Härtl, Holden. 2008. Implizite Informationen. Sprachliche Ökonomie und Interpretative Komplexität bei Verben. (= studia grammatica 68.) Berlin: Akademie.

Haspelmath, Martin. 2011. "The Indeterminacy of Word Segmentation and the Nature of Morphology and Syntax". Folia Linguistica 45:1. 31-80.

Höhle, Tilman. 1982. "Über Komposition und Derivation: Zur Konstituentenstruktur von Wortbildungsprodukten im Deutschen“. Zeitschrift für Sprachwissenschaft 1. 76-112.

Inhoff, Albrecht W., Deborah Briihl \& Jill Schwartz. 1996. "Compound Word Effects Differ in Reading, On-line Naming, and Delayed Naming Tasks". Memory \& Cognition 24:4. 466-476.

Inhoff, Albrecht W., Matthew J. Solomon, Matthew S. Starr \& Lars Placke. 2008. "Eye Movements During the Reading of Compound Words and the Influence of Lexeme Meaning". Memory \& Cognition 36:3. 675-687.

Jacobs, Joachim. 2011. "Grammatik ohne Wörter?". Sprachliches Wissen zwischen Lexikon und Grammatik (= Jahrbuch des Instituts für Deutsche Sprache 2010), ed. by Stefan Engelberg, Anke Holler \& Kristel Proost, 345-372. Berlin, Boston: de Gruyter.

Klos, Verena. 2011. Komposition und Kompositionalität. Möglichkeiten und Grenzen der Semantischen Dekodierung von Substantivkomposita. Berlin: de Gruyter.

Levi, Judith N. 1978. The Syntax and Semantics of Complex Nominals. New York: Academic Press.

Lieber, Rochelle. 1992. Deconstructing Morphology. Word Formation in Syntactic Theory. Chicago: University of Chicago Press.

Lipka, Leonhard. 1977. "Lexikalisierung, Idiomatisierung und Hypostasierung als Probleme einer synchronen Wortbildungslehre". Perspektiven der Wortbildungsforschung, ed. by Brekle, Herbert \& Dieter Kastovsky, 155-164. Bonn: Bouvier.

Marchand, Hans. 1969. The Categories and Types of Present-Day English Word Formation. $2^{\text {nd }}$ ed. München: Beck.

Mondini, Sara, Gonia Jarema, Claudio Luzzatti, Cristina Burani \& Carlo Semenzai. 2002. "Why is Red Cross Different from Yellow Cross? A Neuropsychological Study of Noun-Adjective Agreement within Italian Compounds". Brain and Language 81. 621-634.

Müller-Reichau, Olav. 2006. Sorting the World - on the Relevance of the Kind-Level/Object-Level Distinction to Referential Semantics. Ph.D. dissertation, University of Leipzig.

Payne, John \& Rodney Huddleston. 2002. "Nouns and Noun Phrases". The Cambridge Grammar of the English Language, ed. by Rodney Huddleston \& Geoffrey Pullum, 525-596. Cambridge: Cambridge University Press.

Plag, Ingo, Gero Kunter, Sabine Lappe \& Maria Braun. 2008. "The Role of Semantics, Argument Structure, and Lexicalization in Compound Stress Assignment in English". Language 84:4. 760794.

Plag, Ingo. 2010. "Compound Stress Assignment by Analogy: The Constituent Family Bias". Zeitschrift für Sprachwissenschaft 29:2. 243-282.

Schäfer, Martin. 2009. "A N Constructions in Mandarin and the Compound Versus Phrase Debate". Word Structure 2:2. 272-293.

Schäfer, Martin. 2011. Semantic Transparency and Anaphoric Islands. Submitted manuscript, University of Jena.

Schlücker, Barbara \& Matthias Hüning. 2009. "Compounds and Phrases. A Functional Comparison between German A+N Compounds and Corresponding Phrases". Rivista di Linguistica 21:1. 209234.

Schlücker, Barbara \& Ingo Plag. 2011. "Compound or Phrase? Analogy in Naming“. Lingua 121. 1539-1551. 
Spencer, Andrew. 2003. "Does English Have Productive Compounding?". Topics in Morphology. Selected Papers from the $3^{\text {rd }}$ Mediterranean Morphology Meeting, ed. by Geert E. Booji, Janet DeCesaris, Angela Ralli \& Sergio Scalise, 329-341. Barcelona: Institut Universitari de Lingüística Applicada.

Wunderlich, Dieter. 1986. "Probleme der Wortstruktur". Zeitschrift für Sprachwissenschaft 5. 209252.

Wunderlich, Dieter. 2008. "Spekulationen zum Anfang von Sprache". Zeitschrift für Sprachwissenschaft 27. 229-265.

Zimmer, Karl E. 1971. "Some General Observations about Nominal Compounds". Working Papers on Language Universals. Stanford University 5, C1-C21.

Sven Kotowski

Universität Kassel

Institut für Anglistik / Amerikanistik

Kurt-Wolters-Str. 5

34125 Kassel

Germany

s.kotowski@uni-kassel.de
Katja Böer

Heinrich-Heine-Universität Düsseldorf

Institut für Anglistik / Amerikanistik

Universitätsstr. 1

40225 Düsseldorf

Germany

Katja.Booer@uni-duesseldorf.de

Holden Härtl

Universität Kassel

Institut für Anglistik / Amerikanistik

Kurt-Wolters-Str. 5

34125 Kassel

Germany

holden.haertl@uni-kassel.de 